IRA-International Journal of Technology \& Engineering

ISSN 2455-4480; Vol.04, Issue 03 (2016)

Pg. no. $135-150$

Institute of Research Advances

http://research-advances.org/index.php/IRAJTE

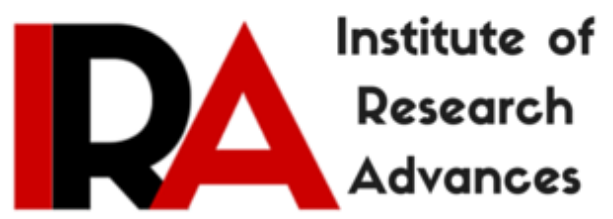

\title{
A Critical Review of the Challenges, Threats, and Drawbacks of Humanoid and Autonomous Robots
}

\author{
Muhammad Ubale Kiru \\ Research Scholar \\ School of Computer Applications \\ Lovely Professional University, India.
}

Type of Reviewed: Peer Reviewed.

DOI: http://dx.doi.org/10.21013/jte.v4.n3.p2

\section{How to cite this paper:}

Kiru, M. (2016). A Critical Review of the Challenges, Threats, and Drawbacks of Humanoid and Autonomous Robots. IRA-International Journal of Technology \& Engineering (ISSN 2455-4480), 4(3), 135-150. doi:http://dx.doi.org/10.21013/jte.v4.n3.p2

(C) Institute of Research Advances

\section{$(\mathrm{cc})$ BY-NC}

This work is licensed under a Creative Commons Attribution-Non Commercial 4.0 International License subject to proper citation to the publication source of the work.

Disclaimer: The scholarly papers as reviewed and published by the Institute of Research Advances (IRA) are the views and opinions of their respective authors and are not the views or opinions of the IRA. The IRA disclaims of any harm or loss caused due to the published content to any party. 


\begin{abstract}
Humanoid and autonomous robots are well known globally not just for their intelligence, but also because they are highly automated and advanced. From the time of their first invention and usage till date, Man has been at the receiving end of their limitations, faults and/or destructiveness. They have caused greater harm than good in some senses, and hence, a rising agitation of their ban. This paper seeks to explore the challenges, risks, problems and drawbacks of the existence and usage of these robots in all aspects of human livelihood; in health, agricultural and social institutes, in attack or defense operations etc. while it dives through some reports by human right organizations and those of the general public, it would consider various revolting voices on why these innovations aren't the cutting edge of human civilization.
\end{abstract}

Keywords: Humanoid robots, Autonomous robots, Co-robot, Weapons, Killer-robot, Botnet, robo-machine.

\title{
1. Introduction
}

Ten years back when robotics is mentioned to many people including myself, the thought of machines with hands and feet would immediately come to mind. But with the passage of time, many have come to understand the fact that robotics is a complex area of study with multifaceted fields. In the late 1970s, the American Robots Association has defined robots as a "Multifunctional operator which can be controlled by programs, which moves materials, components, tools and other special apparatus through control programs" [6]. Robot is also defined as "a reprogrammable, multifunctional manipulator designed to move materials, parts, tools or specialized devices through various programmed functions for the performance of a variety of tasks" (Bowles Physics, 1979) [3]. In its simplest term, a robot is an electromechanical device with multiple degrees-of-freedom (DOF) that is programmable to accomplish a variety of tasks (Bob Williams, 2016) [2]. Similarly, robots are different from machines, although, robots can be referred to as machines in some context. Likewise, machines are more common in labor extensive environment, while robots are more complex, sophisticated and intelligent than machines. But nowadays, robots are also referred to as machines.

Historians believe that the origin of robo-machines or robots could be trace back to 350 B.C when the brilliant and great mathematician Archytas of Tarentum built a mechanical bird dubbed 'The Pigeon' that is propelled by Stream. It is considered as one of the earliest studies of flight [31]. However, the word robot was first coined in 1920 by the Czech novelist named Karel Capek in one of his play titled Rassum's Universal Robots (RUR) [1]. Literally, the word robot was derived from 'robota' which means 'worker, servant or helper' [1]. Perhaps traces of history have proved that $16^{\text {th }}$ century was the era when technology and the ability to craft a sophisticated and advanced machine paved way [24]. Europe and Japan were at forefront in construction of automated dolls. The first invented machines were not actually invented for application in production of goods or to replace human laborers, they were rather invented as a means of entertainment on stage for spectators. Later in 1495, Leonardo DaVinci designed his first mechanical device that looks like an armored knight which was named Leonardo's robot. The logic behind this invention was to imitate a knight as the robot moves [24]. More so, between 1977 to date the invention of Robots have taken a new face, more sophisticated warfare robots were being designed for various purposes. George Lucas's release of Star Wars movie about a universe governed by the force introduces audiences to R2-D2 and C-3PO. The movie is said to have created a new picture of how the next generation robots would look like. Also, from 20002004, the invention of robots moved to the next level. Honda automobiles debuted its first new humanoid robot and Sony on the other hand, released its AIBO ERS-7 robot. Subsequently, 
NASA (an American agency responsible for the civilian space program, aeronautics and aerospace research and development) also launched the MER-A and MER-B for Mars in July 2003 [31] respectively. To date, researches are still being carried out which would come with better versions of the previous generations'. However, with the passage of time, robots are becoming more dangerous and are gradually replacing humans in various facets of human life.

The world is growing very quickly in terms of technological advancements, new innovations are made almost on daily basis, and humanity and nature are becoming useless due to sudden changes in the globe, as robots are dramatically overtaking majority of humans' endeavors. From the past few decades, the world had experienced man's greatest invention which we identify today as 'The Robots'. This invention brings with it the urge for scientists and engineers to see it as a way of solving industrial problems especially in manufacturing industries. Majority of car-producing companies such as Honda, Mercedes, Volkswagen and others had already applied robots in their manufacturing sites. Although, robots are designed for various reasons and applications, and for various functions and environments. Scientists have categorically classified robots into several classes, but each class is categorized based on its function and application. We shall discuss the types of Robots in the subsequent paragraphs. Perhaps for the purpose of this paper we have chosen to elaborate on two types of robots known as Humanoid robots and Autonomous robots.

For many decades now, man considers this invention as the way forward, more or less, a way to make life easier and to make production faster and efficient with regards to time and labor. Prior to the time of their invention, man suffered a lot to get things done, especially for some substantial jobs that has got a lot of risks attached to them. While some people have boosted their production as a result of robotics intervention in their chain of production, many others don't actually look at it this way. Meanwhile, they consider robotics as a means of destroying what humans have built millions of years, they also see these robots as a threat to their means of sustenance, especially if we consider the fact that robots have overtaken majority of human labor in many advanced countries including America (with above 7\%) [20], China and Japan respectively. Perhaps, other risk issues were also raised previously and even today about whether humans are actually safe with robots in their midst or not $[11,15]$. This concern and many others are the focus of this paper. We are going to analyze those risk factors as well as drawbacks in the use of humanoid and autonomous robots. Our center of discussion will be directed to those cases and reports which analyze how harmful robots can become and to also suggest whether it is significantly true that robots can overtake the world in some years to come [30].

On the other hand, it is believed that the advancement of Artificial Intelligence as well as its popularity, researches by scientists are getting high and advanced on the mainstream as well, to the extent that intelligence robots are produced every day for diverse functions within and outside our immediate communities. In the past, intelligent robots were not actually considered as dangerous, as they were mainly designed to solve certain problems or used for medical procedures and other relevant things. But with the advent of artificial neural intelligence, machines are now having ability to think for themselves, make their own decisions, adapt to new environment alongside understanding that environment, so-much-so that they become familiar with everything around them. One important thing to note is that, intelligent robots are also having learning abilities which give them the ability to love, hate and show emotions $[30,29,25$, 12] in certain circumstances and perhaps this is the point where the fear of safety arises. A detailed explanation of such instances shall be discussed in subsequent paragraphs and we will see how these advancements are threatening our lives by trying to overpower humans' natural values and reasons of our existence. 


\section{Humanoid Robots}

Humanoid Robot is one of the most recently emerging and challenging field in Artificial Intelligence and robotics in general. This field has received significant attention and criticism throughout the world during the past few years. Its application has been so far successful. As defined by Hirai et al., 1998 and Hirukawa et al., 2004 Hominoid robots are robots with an overall appearance based on that of human body [16]. In other words Humanoid refers to any being whose body structure resembles that of a human; head, torso, legs, arms and hands. Yet, it is also made to resemble a human both in appearance, actions and behavior [25]. The first humanoid robot to be invented was Elektro, which was introduced in the world show at New York in 1939. Lately, Humanoids robots have been seen in recent popular movies such as AI Artificial Intelligence (2001) by Steven Spielberg, Ex Machina (2015) by Alex Garland, The Machine (2013) by Caradog W. James and lastly the Tamil Indian movie titled Ethiram (The Robot) by S. Shankar. A huge change has been witnessed in these recent years on humanoid robots. They are designed in such a manner that they think and act just like humans. A special neural system scheme is designed for them so that they can operate independently without any human intervention. They also have sense of perception which gives them the ability to adapt to both human environment and machine environment. They are made to act very fast, because their CPU is quite advanced in its form, and therefore give the maximum throughput which has never been given to previous robots before. One good thing about them is their ability to grasp; they are made to learn things so easily, thus, not much of programming is needed in their learning faculty as they can automatically learn by themselves. These robots are used at homes, offices, companies as receptionists, or at telephone companies as customer representatives. Perhaps their complex nature has rapidly become a problem to humans beings because they have abilities to hate, love, or even get emotional, and by so doing they can act on their own will, depending on how they are treated by the people who interact with them. And if a robot can think by itself then it means it does not need any one to command it or stop it from doing something or hurting someone. Related example has been seen in the above mentioned movies where the robots become obsessed with people and then end up hurting them thinking that they are doing the right thing [12]. [See figure 1]

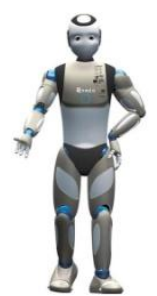

An example of a Humanoid Robots. [Figure 1]

Now coming to their characteristics, humanoid robots are basically characterized by sensors which allow them to sense their immediate surroundings. These sensors represent various components of the robot which include light sensor for sight, touch and pressure sensor, chemical sensors for perception of smell and hearing and indeed sonar sensors for hearing [8]. Another important feature is the act of movement; robots' movement is usually supported by rolling wheels, walking on legs or propelling by thrusters. Other parts include the arms which helps the robot in most of its activities. Furthermore, robots need some source of energy to power itself. Some robots use solar energy while others have a power reservoir or in some cases rechargeable batteries. The most important amongst all the components that make robot fully functional and smart is the artificial intelligence also known as artificial neutral system. This neural system is generated from the millions of lines of code which are programmed into the neural network of the robot. The neural system in robots is similar as that of human nervous system, and it helps them 
in receiving and sending millions of inputs and outputs. It is said that some robots are even connected to knowledge-based system known as the Blue-Book [25], something more like a search engine which processes all the responses whenever questions are asked to the machine. It is very crucial to note that if the programming is good then there is high chance that the machine will perform beyond expectations. In most of the cases the complexity of the algorithm plays an important role in this aspect. Moreover, there is the actuator; the actuator is a "mechanism for activating process control equipment by the use of pneumatic, hydraulic or electronic signals" [32]. So the actuators are used for providing strength and energy to all the joints that are connected with one another. Another key component is the wireless receiver which allows direct access to the machine, or enables the machine to have link with local as well as global networks [5]. Some of their examples include the popular Honda's ASIMO, first introduced in October 2000 [2]. More so, another massive robot which history will never forget is SARCOS; this robot was actually designed for the purpose of research and entertainment in several U.S. universities and research institutes [5].

\section{Autonomous Robots}

The robotics industries have been producing thousands of robots, ever since they started, yet still facing some challenges that till today, remain unsolved [8]. One of the key problems which remain unanswered is the increasing cases of death and calamities caused by one of their creation known as Autonomous Robots. According to George A. Bekey, a Professor Emeritus in Computer science at university of Southern California, he defines autonomous robots as "Intelligent machines are capable of performing tasks in the real world by themselves, without explicit human control" [33]. Autonomous machine in most cases have the ability to retrieve information about their immediate environment using their artificial consciousness. They are programmed to determine their own actions by making decisions after considering all options. They are also likely to adapt to any kind of changes within the environment, whether favorable or otherwise [32]. The term autonomous as elaborated by a report prepared by the U.S. department of Navy which describes the term autonomy "as the capability to operate in the real world environment without any form of external control, once the machine is activated and at least in some areas of operation, for extended period of time" [9]. In most of the cases, autonomous robots are used by Army as weapons, hospitals for conducting surgeries and procedures on patients and in large manufacturing industries for labor extensive works or as apparatus. Furthermore, autonomous robots are so intelligent as they are designed with learning abilities, these abilities give them the capacity to distinguish between objects so that proper action is taken accordingly. Although there are concerns raised by many with regard to how autonomous machines operate. In 2012, comments by concerned people were submitted in a rejoinder titled 'The Evitability of autonomous robot warfare' by Noel E. Sharkey, a Professor of Artificial Intelligence and Robotics at Sheffield University. Noel opens the first paragraph of the paper by saying "This is a call for the prohibition of autonomous lethal targeting by freeranging robots" [10]. The major issues raised were that autonomous armed robots cannot discriminate between combatants and non-combatants or other immune actors such as service workers, retirees and victims that are wounded, or have surrendered in a way that would satisfy the principle of distinction [10]. He supports his claim by citing reference with the Israel Harpy. It is a loitering munition that detects radar signal. When it finds one, it consults its knowledge-base to make comparison, whether objects are friendly or not, if it is not, it dive bombs the radar [10].

Similarly, Common Wealth of Massachusetts under the Board of Registration in Medicine submits an advisory report on Robot-assisted surgery expressing concern on cases of autonomous robots harming patients during surgery [7]. According to the report, for two years, the Quality and Patient Safety and Division (QPSD) has received an increasing number of Safety and Quality 
(SQR) reports of patients complications associated with robot-assisted surgery. The main aim of this advisory is to draw the attention on some incidents involving robot-assisted surgeries, so as to show some lessons learned in order to avoid future occurrence of such potential cases. This report shows that involvement of robot-assisted surgery has enormous advantages such as ease of work, accuracy and so on. Yet, they carry risks of complications and poor outcomes. Among the several cases pointed out, one of them was the case of a patient "who underwent robotic proctosigmoidectomy for refractory ulcerative colitis; resected rectal tissue was inadvertently left in the abdomen and was not detected during visual sweep using the robot before closure" [7]. Later in the day, the surgeon in-charge of the patient realized the error and the patient had to undergo the same procedure later in the day. So now, the point we are trying to raise is, the autonomous robots in spite of all careful research on how to improve them, they cannot be $100 \%$ perfect as we want them to be; therefore dangerous for such usage. [See figure 2]
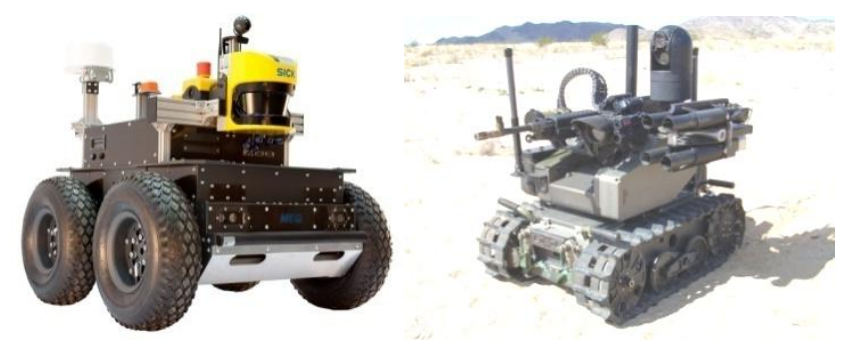

An Example of RoMegAt Autonomous War Robots [figure 2]

\section{Types Of Robots}

Robotics is a very wide and broad area, as it comprises of different fields and has been adapted by many professional bodies including defense, medicine, agriculture, automobile, aeronautics, etc. This is why there are no specific types of robots. Hence, we cannot categorically say these are the types of robots because types of robots are measured in terms of their use, functions, environment and location system they possess $[14,17,34]$. Thus, here are the basic types of robots viz: Stationary robots, wheeled robots, legged robots, Vehicle robots, Cloud robots, and Nano robots.

\section{A. Stationary Robots}

These are types of robots which are considered static, meaning they do not move or change position during operation. Some of them include surgical robots which are often found in hospitals. Another category that can fall here is security detection robots which are stationed to detect unauthorized access within a given environment. Other examples include commercial robots, Cartesian robots, cylindrical robots, and parallel robots and so on.

B. Wheeled Robots

These types of robots are said to be locomotive in nature. They change their position with the help of wheels, which make it easier for them to move from one place to another. Some of their examples include single wheel robots, two wheel, and military robots and so on.

\section{Legged robots}

These robots are considered the most complex and sophisticated when it comes to locomotion. They are also known as mobile robots as they can move from place to place on a very quick speed. They are often characterized by having legs and arms which support their movement or allow them to get up when they fall down. The most common legged robots in this category are the popular humanoid robots, military robots, and domestic or household robots [34]. 


\section{Vehicle Robots}

This category of robot is considered as one of the largest of all, they include those robots which cover far distance. They have such locomotive components that could endure any kind of environment, be it rocky areas, deserts, water or even space. Example of these robots include

- Space robots - ones used in the space by NASA

- Flying robots - like drones, Aerial robots etc.

- Undersea robots- ones used in underwater like oceans

- Bomb Squad robots - ones used for disarming bombs

\section{E. Cloud robots}

These are "group of robots or devices that are connected via a wired and or wireless communication networks" [17]. These types of robots are usually controlled by a human controller who remotely controls and manipulate them by sending commands as inputs and receiving output through a communication channel. Robots within this category can communicate even among themselves, they can exchange information and they can make a collective decision [30] as it's recorded in the Tamil movie Enthiran [30]. Lots of researches prove that they can violate orders and operate autonomously without human intervention which can lead to harm.

\section{F. Nano robots}

A Nano robot is a tiny machine designed to perform a specific task repeatedly and with precision at nano scale dimension typically between 1 and 100 Nanometers [35]. From the time of its discovery till date Nano technology has changed the globe with its overwhelming application into various fields of research. Today, Nano robots can be used to perform surgical procedures that are beyond Doctors' reach, such as Tumor treatment and Arteriosclerosis. Furthermore, now technology is so advanced that Nano robots are used in warfare to build atomic bombs, armors and other defense elements.

\section{Literature Survey}

It is without any doubt that robots have contributed to the human advancement right from their time of invention till date. We must acknowledge the fact that some good and well programmed robots have saved lives and properties. Today world's largest automobile companies depend on robots for production, and that makes life much easier and better, at least laborers are saved from all forms of occupational hazards. However, in these recent years, a lot of questions and concerns have been raised by observers including some scientists that, existence of robots is becoming disastrous to humans' safety. Moreover, lots of papers have been written calling off the operations of certain types of robots after foreseeing that robots are dramatically replacing human beings in most of the aspects of life. Initially the idea of robots was to aid man in his endeavors, but later, the course began to take a new direction.

In one of those campaign reports for the stop of robots, Merel Ekelhof and Mariam Struyk open their paper with the quotation "first, you has human beings without machines, then you had humans being with machines, and finally you have machines without human beings". (John Pike 2005) [27]. They observed that, experts have predicted that, the use of robot weapons which is also known as killer robots will become fully established in the next 20 years. They reported that in November 2012, the U.S. Department of Defense published its first public policy on robotic weaponized system; this policy suggests that robots used in war should be limited to only delivery of non-lethal force, unless otherwise decided by the department officials. They further 
venerated that, the application and deployment of fully autonomous robots has raised a serious ethical, legal and technical concern. They deducted that, with the publication of a report on drones in May 2011 by PAX; regarding the issues of fully autonomous weapons, several other reports were submitted from 2011 to 2013 such as the report of International Spectator, Human Right Watch, Harvard Law School, International Human Right Clinic, International committee of Robots Arms control, all agitating to stop killer robots.

Laurel D. Riek also published a similar paper titled 'The social co-robotics problem space' where the paper highlights six major key challenges found with the use of robots. Laurel argues that in order to continue this journey of man-robot relationship, it is important that our research community fully define the problem space and articulate its inherent challenges [23]. Meanwhile, we must determine the ways to address these challenges before moving forward. Although the focus of Laurel's paper is on co-robots in human social environment, therefore highlights some key challenges as follows: (1) Dynamic space - if social co-robots must interact with human being and their environment, then human being as complex as they are create an unforeseen challenges to the robots which are often inadaptable to the social co-robots. (2) Social learning one huge task that is shouldered in social co-robots is the ability to learn and adapt not only to their environment but also co-humans within it. Every time new people come to the community, it is a difficult task for the co-robots to be able to recognize these people, otherwise, it can harm them in a way (3) Affects and Social Signal Awareness - Laurel says "one of the commonly explored problems in social robotics concern the recognition and synthesis of affect and social signal" [23]. A well programmed co-robot should be able to infer meaning [23] from a human's face, gaze, posture, gestures etc. in order to generate its own actions. If it cannot do that, then it fails.

In furtherance of this discussion, it is paramount to bring to the attention of the readers about a very significant article which attracted the attention of the world's leaders on a campaign to stop killer robots and other similar robots. The article titled 'Country Statement on killer robots' contains statements of concerns made by governments of multilateral meetings on the topic of fully lethal autonomous weapons system, this include agencies like European Union and Organization of Islamic conference. It is reported that, a total of 44 nations spoke to forward their views on this subject matter. These statements were said to be made in occasions like: (1) A human right Council debate on the UN report by Prof. Christof Heyns in Geneva on $30^{\text {th }}$ may 2013. (2) The United National Geneva General Assembly first committee on Disarmament and International Security in New York during October 2014. (3) Convention on Conventional weapons meeting of high contracting parties and related meeting in Geneva during November 2013 [11]. Thus, the entire 44 countries submit that, the ban on robots in battlefields should be enacted as the robots are not fully taking responsibilities during war. So the questions is who is responsible for the crimes committed as a result of robots taking wrong actions, it is the war commander, the programmer, or the robots?[9] if however, no one can take these responsibilities then the negative consequences would be unbearable. Therefore the ban on robots is at our best interest.

Before concluding this review, it is necessary to mention two $21^{\text {st }}$ century movies which directly reflect our topic of discussion. The Machine (2013), a movie directed by Caradog W. James which depicts an "effort to construct a perfect android killing machine in a war against China, UK scientists exceed their goal and create a sentient Cyborg" [29]. This humanoid machine is designed to learn things within its environment. Alongside get trained to kill enemies in combat field. The movie ends with the Cyborg machine conspiring to end the existence of human race, starting by eliminating the agency staff that created it and also takes over the control of other robots and gives them kill orders on any human being. The other movie is titled 'Ex-machina', 
which is rated as one of the best science fiction movies of 2015, directed by Alex Garland. The movie depicts a young programmer who is selected to participate in a ground breaking experiment in synthetic intelligence by evaluating the human quality of a well-designed humanoid robot [25]. This robot gives an outstanding result during a Turing Test evaluation it took several times. It indeed has the ability to love, hate and to detect when someone lies and so on. In the end, it feels it deserves some freedom to live among humans, therefore kills its maker and escapes custody. So, this and other similar examples are some of the facts that make experts to condemn the existence of humanoid and autonomous robots, because they can hurt due to their freewill, and they can easily get confused and the outcome is always not a good one [25].

\section{Key Issues And Problems In Robots}

After much study and consultation, I come to understand that robots are much safer in manufacturing sector and in companies rather than homes and communities. I therefore urge that humanoid and autonomous robots should be stopped due to the following carefully selected points of mine:

A. Health Care Industry

Technological advancements have necessitated humans to apply robots as part of medical health care facilities. It is more like saying robots are replacing human doctors in some aspects of managing patients and by assisting in complicated procedures and surgeries. And it is without doubt that robots are the future of health care. But lots of questions are raised to question their capabilities. Graham Ross a technical advisor and Professor at Blue Sky Poway California in a bulletin cautions that "the health care industry is unlikely to adapt robots unless the risk and investment are small, and concrete evidence of success is needed before taking on the larger opportunity" [36]. He added that the uncertainty and risks attached to the outcome is more than the benefits. Well, it is absolutely true! To add to that, these robots in question are just mere machines with a little chip that is programmed, they are not whatsoever assisted by anyone, unless in few cases. And we all know programmed objects often fail even after several testing and evaluation. Also, experience is the best teacher according to a wise saying. If the robots come across a new problem which is not programmed in its chip, what do we think would be the outcome? Furthermore, it is crucial to also note that due to their complex nature these robots contain a lot of radiation and we recently come to know that radiation has a serious ramification in human body. So the patient might get more exposed to harm than good.

Let's put these robots to test. It is a fact that robots are made with consciousness but are they as conscious as a human doctor? Secondly, can they be able to perfectly detect mistakes or errors during operation? The answers are no. let's take for instance the popular case of da Vinci Surgery. The da Vinci surgical robot helps doctors perform complex surgeries that take long period of time. According to the inventers of da Vinci robot "the robot comes with all the tools a surgeon needs to perform a complete set of complex surgeries" [38]. In 2013, a lawsuit was raised due to a study published in the Journal for Healthcare Quality which found " 245 robotic surgery problems - including 71 deaths and 174 non-fatal injuries which were reported to FDA" [37]. In a different lawsuit, one among some 2009 cases, a patient was recorded dead during robotic surgery, but the report was not filed until 2010 after a journal broke the news [37]. However, the report submits that the complications came as a result of (1) Hemorrhage, (2) infection, (3) cardiac arrest, (4) multi-organ failure, (5) pulmonary embolus, [37] and the short comings mentioned include longer operation time, conversion to another surgical technique, larger incision, breaking problems and additional times under anesthesia [38]. 


\section{B. Economic and financial issues}

Several industries around the world have actually increased their revenues by simply deploying robots in their chain of production. It is a remarkable achievement that ever happened to the manufacturing industries. The use of robots in offices and companies has become inevitable these days. In fact, the International Federation of Robotics reported that companies in South Korea employed 437 industrial robots for every 10,000 manufacturing workers in 2013 [39]. This figure actually sounds threatening right? Well it is indeed threatening. In fact, Jeremy Rifkin in the end of work to Martin Ford in the Rise of the Robots, predicts that "automation will make human jobs at least as we know them today - obsolete in the not too distant future"[40]. In United State alone, it is said that "manufacturing jobs have drastically fallen from $25 \%$ of the total in 1970 to approximately $10 \%$ today, which implies that $47 \%$ of U.S. jobs are at risk due to computerization" $[40,20]$.

Looking at the issues from the financial point of view, creating a robot actually demands huge investment. This is why majority of companies who decide to deploy robots need to have a long term plan, including firing at least half of their staff, so that all their salaries could be diverted to funding projects for creating robots. Robots can actually serve the purpose, but their maintenance is also as problematic as getting them. The fear is not for the cost of investment par say, it is rather, for the consequences which come along with it. So, gradually the prediction that robots will replace human is eventually becoming a reality. Such predictions have also been portrayed in the Tamil movie titled, Enthiran (The robot) by S. Shankar where a humanoid robot after gaining freedom begins to creating more robots under his command. At the long run, these robots ended up hurt lots of people by causing the death of hundreds of Indians. Hence the Indian government decides to shut down the project after considering facts produced by experts condemning humanoid robots $[30,4]$.

\section{Social issues}

In the social aspect of robotic problem, we will talk about a specific type of humanoid robot known as Social co-robot [23]. A social co-robot is a special type of humanoid robot that can be deployed within social communities in order to interact with human beings by rendering assistance to them. These robots are designed with human consciousness which gives them the ability to learn things within their neighborhood. However, they are used as personal assistants, community workers, home delivery agents, local conveyance and so on [23]. Some special features about them are, they have learnability and consciousness which enable them to have feelings, emotions, and desire for self-control $[30,29,25,12]$ but with all these artificial features in place, experts believe there are lots of unseen challenges that are likely to cause many encounters

- Familiarity - Community is a large area which encompasses lots of people, objects, both living and non-living. New people come and some leave as time goes by. With this, most robots find it difficult to identify strangers, especially community members. Therefore if the aim is for the robot to ensure security then there is likelihood that the robot cannot identify all the people around [23].

- Distinction - No matter how well programmed a robot is, it is difficult for it to distinguish between harmful objects and harmless object. For instance, if a robot is used as a police, then it is very difficult for it to segregate between a target and an innocent man moving with a stick [27]. Also, recent reports prove that robots cannot detect body languages such as gestures, gaze, and facial emotions and so on. 
- Social right - Social rights and taking responsibilities is still an unsorted matter in robotics. Many reports have been submitted regarding who to be blamed for crimes committed by robots [9]. The question raised is should we blame the commander, the programmer, or the robot [27].

- Acceptance - This issue has posed a serious challenge, therefore I will approach this issue in two ways. (1) Laurel D. reveals in his paper [28] that some social environment do not accept robots. He even laments a story of how delivery robots get scolded in certain communities. As it is mentioned that some robots are programmed to defend themselves in cases of a direct attack. And if such case happens then only God knows what the consequence might be. (2) Study reveals that some people especially scientists have begun to build robots to replace their loved ones who already passed away [12]. The idea here is to reduce the pain and tension they are undergoing as a result. These types of robots are designed to love the people around them, they also feel loved in return, they have emotions, they even cry, they react to anger, they lose patience sometimes and they can hurt others as well [12]. In another adventure, predictions show that sooner or later robots will be built to serve the role of sex workers. They will have same sexual organs as humans, they will also have feelings and desires as women and men do, and the person involved with them might never know they are robots. [25, 12].

\section{Warfare issues}

In robotics, there are groups or types of robots that are called killer robots. These types of robots are used in war fields and or as defense systems. These robots are designed to independently select and engage their targets without human intervention [27]. This implies that they don't operate on human orders, but on their own intrinsic decision; whether the decision could cause destruction or not. Vincent Muller says [19] "since the 1970, there were automated radar-guarded gun system to defend ships". Today, we have these machines that can automatically identify and attack oncoming missile, rockets, and aircraft and so on [19]. Now these systems are rapidly becoming popular, as UK, US, China, Israel, and Russia etc. have already moved forward with their invention. So, if we look at it in the other way round, many questions and complaints were raised by different human right organizations and even countries showing their disinterestedness in these innovations. In contrast, campaign to stop killer robots has already started in some parts of the world. As mentioned earlier, now about 44 countries so far signed papers disapproving the continuance of such projects [11]. So, why warfare robot should be banned? Here are some reasons based on the different submission by different critics:

\section{- Lack of conscience}

I will start by quoting Armin Krishnan, a political scientist specialized in defense, International Security and Intelligence, he says "An action so serious in its consequences should not be left to mindless machines" [27] mind conscious is something we cannot acquire artificially, we might try but we cannot be perfect. The notion that machines will have consciousness is just a story which will never come true. According to UN special Repporteur Heyns "our moral objection against robots may from the fact that decision over life and death in armed conflict require compassion and intuition". While adding to that "humans- while they are fallible - at least might possess these qualities, whereas robots definitely do not" [27] 
- Unpredictable actions

When you set free a machine with neither consciousness nor conscience to chase people in war zone, what do you think is the outcome? Prof. Stuart of University of California regarding unpredictable actions says "imagine turning on TV and seeing footage from urban battlefield, where robots are hunting down and killing unarmed children" [41]. Recently, the number for those not in support of killer robots outnumbered that of those in support of it. It is quoted that in July 2015, over 3000 experts in Artificial Intelligence and robotics scientists including several members of the forum for Global Agenda Council on Artificial Intelligence and Robotics were said to have signed an open letter calling for a complete ban on lethal autonomous machines [41]. Stuart Russell adds that, later other 17,000 signatories from other fields comprising physics, philosophy, law, electronics, including the famous linguist Noam Chomsky [41].

Another issue worth mentioning is the issue of self-defense. ASIMOV's law of robots permits [9] "Robot to defend themselves where that action did not conflict with higher duties". This implies that they can go extra miles to do what is necessary to protect their selves. In some case, it might not even be a threat, but the machine will perceive the situation as so.

- Machine failure and non-compliance to order

In several occasions machines were said to have failed during operations completely. There are numerous reasons that could cause machine to fail; bad coding is one of them. Most recent development shows that some machines if affected by worms or viruses can crash them down and thus, lead to their failure. In April 2008, several TALON SWORD unit-mobile robots armed with machine guns were said to have failed, although the reason of their failure was not disclosed (because they are highly classified) [9].

In October 2007, a semi-automated robotic cannon deployed by South African army also failed, end up killing a soldier and wounding 14 others in what we call friendly fire [9]. In another similar incident, a commander orders a robot to launch an attack on a house known to be a base for insurgents, the robot being equipped with infrared scanners; sensors that could detect movement through the walls, detects that there were children in the house, and thus disregards the order [9]. So the question here is, what if the children were dangerously armed? just like it happens in some countries like Somalia?

- Legal challenges and Law of robots

Legal challenges in robots have been a topic of debate for many decades. As mentioned earlier someone must be held accountable for any crime committed by robots. Otherwise, kill orders will be given to robots and casualties would keep increasing and no one will take responsibility. Hence, if we cannot control our creation then why create them in the first place? It is of utmost importance that we mention the 3 Laws of Robots as suggested by Isaac Asimov:

1. A robot may not injure a human being or through inaction allow a human to come to harm,

2. A robot must obey orders given to it by human beings except where such orders would conflict with the first law,

3. And a robot must protect its own existence as long as such protection does not conflict with the first or second law [15]. 
Looking at these laws, any intelligent person will know that man has no control over the robots. For instance the first and the second laws are contradicting each other, because the robots have already broken that laws several times. How could someone build a killer robot, name it killer robot, equip it with guns and then tell it not to kill? How is that possible? As for the third law, it indirectly says robot's existence supersedes that of man the moment it says robot should protect itself at all cost

\section{Conclusion}

In the course of this analysis and study, I came to understand that robot is man's worse invention based on the fact that robots' actions have caused many to lose their lives. Several memos, letters and reports which we have mentioned and many others unmentioned are enough to prove the above assertion. Perhaps, it is quite an ideal notion to have industrial robots that can minimize human exposure to risks, boost productivity and increase profit. But it is out of mind to create or build something that is threatening to the existence of even its maker. We have seen in the end of Ex-Machina, The Machine, and Chappie (movies) how in the quest to gain freedom, machines revolt against their makers and even think of reproducing themselves. Their actions in reality will do nothing but endanger man and his safety.

Another lesson learned from their drawbacks is the issue of security. I want to use this opportunity to point out two important lessons. (1) Our study on various materials show that security breaches that are often found in the neural scheme of the robots can be used as vulnerability by hackers to override the original mission of the robot [30]. And if robot's control can be overtaken in the middle of battle field then terrible consequences should be expected. (2) My second concern is how robots are connected to the network. Suppose a robot is directly connected to the global network or the internet, this means it can be controlled remotely and perhaps gets hijacked by hackers, if access is gained, then same access can be traced back to the main frame machine or server machine that is aiding the control of the robot. Hence, the robot can be used as a zombie (intermediary) to launch a bigger attack on innocent people. So, until and unless these problems are solved robots will remain vulnerable to attacks. More so, there are advanced cloud robots that get attacked through a mechanism known as Botnet [17]. Botnet attack is when a collection of comprised machines called zombies are infected with a malware that allow an attacker to remotely inspire the machines to do something inappropriate such as attack, this is what is called botnet attack. However, if such machines are peered together, they can cause a massive destruction which might take a long time to reverse. One might ask; how can this happen, studied evidence shows that [21] if machines are connected together, there are high chances that they can exchange information that can be of help coordinate an attack on anything including human race.

Another good point worth mentioning is about robot's consciousness. Several tests proved that machines are vulnerable to Social engineering (an act of using trick and deception to extract information from someone or something) attacks as it has been seen in the movies titled Enthiran. The humanoid robot could not differentiate normal conversation from abnormal one that could lead to the exposure of the machine schematics [30]. Lots of robot know about themselves more than they should know, therefore if care is not taking, then can say even the most confidential things they know. Finally, I am calling on the concerned bodies to revisit their decisions on building such robots; they should at least consider the future generations to come. They should also consider the consequences of what robots could cause including unemployment, increase in crime rates and fatal accidents that could lead to death. 


\section{Bibliography}

[1]. Vikram Kapila, "Introduction to Robotics", [Online], Available: http://www. engineering.nyu.edu

[2]. Bob Williams, "An Introduction to Robotics", Mechanics and Control of Robotics Manipulators, Dr. Bob Productions, unpublished.

[3]. Julian Roosa, "Security Risks of Utilizing Robotics and Medical Devices in the Medical Profession”, M.S. thesis, Davenport University.

[4]. Jackrit Suthakorn, "Robotics in Medical Applications". Applied Research Laboratories of Biomedical and Robotics Technology, Mahidol University, Salaya, Nakorn Patom 73170 Thailand.

[5]. “Anonymous, Humanoid Robots”, [Online], Available: http:// www. ebookinga .com /pdf / irobot

[6]. "Anonymous, Introduction to Robotics", [Online], Available: http:// www. sciencekits .com/ robots1. html

[7]. “Advisory on Robot-Assisted Surgery”, Common Wealth of Massachusetts, US: Quality and Patient Safety Division.

[8]. J. T. Samuel, "Advancements in Robotics and its future uses", International Journal of Science and Engineering Research, Vol. 2, issues 8, ISSN 2229-5518

[9]. Patrick Lin, et al, “Autonomous Military Robotics: Risk, Ethics, and Design”, Prepared For: US Department of Navy, Office of Naval Research, version 1.0.9, December 2008.

[10]. E. N. Sharkey, "The Evitability of Autonomous Robots Warfare”, Property of International Review of the Red Cross. Vol. 94, Number 889 summer 2012

[11]. Campaign Stop Killer Robots, Country Statements on Killer Robots, Campaign to stop killer Robots, March 2014.

[12]. Steven Spielberg, Haley Joel Osment and Jude Law, IMDb “A.I. Artificial Intelligence", [Online], Availbale: http://www.imdb.com/title/tt0212720/>.

[13]. "Introduction to Robotics", Technology Subjects support services, T4 Galway Education Centre.

[14]. R. J. Ali, "Robotics, From Industrial Robots to Humanoids", Biomedical Engineering Department, NED University of Engineering \& technology.

[15]. Neill Blomkamp, "Chappie”, [Online], available: http: // www. imdb.com/title/tt1823672/, 2016.

[16]. L. Senad and S. Christopher, "Humanoid Robots", [Online], available: http://www.Informatik.uni-hmburg.de 
[17]. H. Guoqiang et al, "Cloud Robotics: Architecture, Challenges and Applications", [Online], available: ieeexplore. ieee. org

[18]. B. Tamara et al, "To Make a Robot Secure: An Experimental Analysis of Cyber Security Threats against Teleoperated Surgical Robotics", May 2015.

[19]. C. V. Muller \& W. T. Simpsons, “Autonomous Killer Robots Are Probably Good news”, Drafted 2014

[20]. M. Ben and A. Robert, “Are Robots Taking Our Jobs, or Making them?” The Information Technology \& Innovation Foundation, 2013

[21]. G. R. Epstein, "The Cases of the Killer Robot”, West Chester University of PA, 19383, 1994

[22]. S. Robert, “Killer Robot”, Journal of Applied Philosophy, Vol. 24, No. 1, 2007.

[23]. D. L. Riek, “The Social Co-Robotics Problem Space: Six Key Challenges”.

[24]. G. Volker and8 B. Rainer, "Past, Present and Future of Intelligent Robots". CIRA 2003, Kobe.

[25]. Ex Machina. Hollywood movie: Alex Garland, 2015.

[26]. Inman Harvey, "Evolving Robots Consciousness: The Easy Problems and the Rest".

[27]. M. Ekelhof and M. Struyk, "Deadly Decisions: 8 Objectives to Killer Robots", Internet: www.scribd.com, June 25, 2016.

[29]. The Machine. Hollywood movie: Caradog W. James, 2013.

[30]. Enthiran. Bollywood/Tamil movie: S. Shankar, 2010.

[31] . J. I., "A Brief History of Robotics", Internet: http://robotics.megagiant.com/history.html, June 23, 2016.

[32]. R. W. "ROBOT ACTUATORS - DIFFERENT TYPES". Internet: https: //www. robots. com/ education/ actuators, June 24, 2016,

[33]. A. G. B, “Autonomous Robots”, Internet: https:// mitpress.mit.edu/books/autonomousrobots, June 25, 2016,

[34]. R. P., "All Types Of Robots". Internet: http:// www. robotpark.com/All-Types-Of-Robots, June 26, 2016.

[35]. Margaret Rouse, "Nano Robot.", Internet: http:// www. easybib.com/mla-format/websitecitation, May 2007.

[36]. Graham Ross, "Robotics in Healthcare: Challenges and Opportunities", Internet: http:// medicaldesign. com/ archive/robotics-healthcare-challenges-and-opportunities-0, 27 June 2016. 
[37]. "Da Vinci Surgery Problems." Surgical Watch. Internet: http://surgicalwatch.com/davincirobot/surgery-problems, 8 May 2014.

[38]. "Da Vinci Robotic Surgery." Drugwatch.com, Internet: https://www.drugwatch.com/davinci-surgery, 27 June 2016.

[39]. Patrick Marshall, "Robotics and the Economy" CQ Researcher, Internet: http:// library. cqpress.com/ cqresearch, 27 June 2016.

[40]. Xavier Mesnard, "What Happens When Robots Take Our Jobs?" World Economic Forum, Internet: https://www.weforum.org/agenda, 27 June 2016.

[41]. Stuart Russell, "Robots in War: The next Weapons of Mass Destruction?" World Economic Forum, Internet: https://www.weforum.org/agenda/2016/01/robots-in-war-the-next-weapons-ofmass-destruction, 28 June 2016.

[42]. "Botnet", Redware, Internet: https:// security. radware. com /ddos-knowledgecenter/ddospedia/botnet, 28 June 2016. 